\title{
Psychometric properties of the Turkish Form of the Observational Collective Efficacy Scale for Sports
}

\author{
Umut Sezer $^{1, *}$, Serdar Kocaekşi ${ }^{1}$, Ramazan Taşçığlü ${ }^{1}$, Ayșe F. Özbal ${ }^{2}$, and Evrensel Heper ${ }^{1}$ \\ ${ }^{1}$ Faculty of Sport Sciences, Eskişehir Technical University, Eskişehir, Turkey; and ${ }^{2}$ Faculty of Sport Sciences, Kastamonu \\ University, Kastamonu, Turkey
}

Copyright: (c) 2020 U. Sezer et al. This is an open access article licensed under the Creative Commons Attribution License (https://creativecommons.org/licenses/by/4.0/).

\begin{abstract}
Background: Recent findings suggest that collective efficacy is a dynamic construct that is encompassed with process and outcome-oriented behaviors. Observational Collective Efficacy Scale for Sports (OCESS) is a tool that encapsulates process-oriented behaviors in the measurement of collective efficacy. Objective: The present study aims to carry out a cultural adaptation and assess the validity and reliability of the Turkish form of the OCESS in a variety of team sports. Methods: A convenience sample of 219 athletes (age $M=21.29, S D=3.80$ years) from team sports aged 18 years or older ( 78 female, age $M=21.17, S D=2.74$ years; 141 male, age $M=21.36, S D=4.29$ years) participated in the study. OCESS is a unidimensional measure of collective efficacy consists of 5 items in a 7-point Likert format. Confirmatory factor analysis was used to test the factor structure of the OCESS, convergent and discriminant validities were evaluated by using composite reliability (CR), average variance extracted (AVE), maximum shared variance (MSV) and average shared variance (ASV) values. Internal consistency of the OCESS was assessed by Cronbach's alpha coefficient and composite reliability, together with item-total correlations. Test-retest reliability was examined by calculating intra-class correlation coefficient. Results: The goodness-of-fit indices from the confirmatory factor analysis revealed that one-factor measurement model fit the data satisfactorily. Evidence for convergent and discriminant validity was provided by CR, AVE, MSV, and ASV. Coefficient alpha and composite reliability for the measure were calculated as .80 and .82 , respectively. Corrected item-total correlations ranged from .36 to .71 and a $t$-test was carried out with each item's means of upper $27 \%$ and lower $27 \%$ showed significant differences. The Turkish version of the OCESS showed excellent test-retest reliability over a 1-week time interval. Conclusions: This study demonstrates that the Turkish version of the OCESS is a valid and reliable measure of collective efficacy for sports.
\end{abstract}

Keywords: observational measurement, process-oriented behaviors, efficacy beliefs, team sports, scale adaptation

\section{Introduction}

A common phrase that clearly denotes a successful performance in sports is "to believe in achieving the targeted performance". This statement, indeed, refers to the term "efficacy", which is one of the components of "belief" when considered from the perspective of sports psychology. According to Bandura, efficacy beliefs are individuals' self-perceptions about their own abilities to carry out particular tasks and could enhance motivation and performance. Grounded in social cognitive theory, efficacy refers to a mechanism affecting individuals'

\footnotetext{
* Address for correspondence: Umut Sezer, Faculty of Sport Sciences, Eskişehir Technical University, İki Eylül Kampüsü Gazipaşa Mh. Spor Bilimleri Fakültesi 26555, Turkey. E-mail: umutsezer@eskisehir.edu.tr
}

tendency to assume responsibilities in fulfilling a task, how much effort they will make, and how much they will insist on completing this task despite failures (Chow \& Feltz, 2014). Research on efficacy identifies two forms of efficacy beliefs, namely self-efficacy and collective efficacy. The former is about personal capacity and the potentials that might trigger the orientation of individuals' behavior and the latter, which is the focus of the current study, is defined as the common belief of a group towards their capabilities to organize and execute a course of actions required to accomplish certain tasks successfully (Bandura, 1997). In other words, self-efficacy determines how an individual feels, how he motivates himself and how he behaves. On the other hand, collective efficacy stems from the research on selfefficacy and has been reported that teams with strong collective efficacy set more challenging goals (Silver \& 
Bufanio, 1996), try harder to achieve these goals and are more determined against challenging situations (Greenless, Graydon, \& Maynard, 1999). Similarly, athletes that trust in the efficacy of their team perform better (Dithurbide, Sullivan, \& Chow, 2009). Meta-analysis studies on group unity and group performance showed that consistent collective efficacy has positive effects on group performance (Gully, Incalcaterra, Joshi, \& Beaubien 2002; Stajkovic, Lee, \& Nyberg, 2009). Collective efficacy is a construct at the group level and reflects the perceptions of group members about their conjoint capabilities (Beauchamp, 2007).

The literature review showed the data collection instruments measuring collective efficacy are often based on Bandura's (1997) definition. Accordingly, a number of measurement tools were developed to assess the following issues: to identify behavior patterns during a performance that are peculiar to the dynamics of collective efficacy; and team members' trust in their abilities while achieving predetermined goals (Fransen, Kleinert, Dithurbide, Vanbeselaere, \& Boen, 2014; Short, Sullivan, \& Feltz, 2005). While the former focuses on shared behaviors and experiences, the latter is about an outcome-oriented focusing on goals to be achieved as a team (Fransen et al., 2014).

Due to its dynamic structure, collective efficacy might change within weeks or days; even during a match. Although there are studies focusing on measuring collective efficacy prior to sports events, no studies were conducted to measure collective efficacy during sports events except the study by Edmonds, Tenenbaum, Kamata, and Johnson (2009), see Fransen et al. (2014). In this study, Edmonds et al. (2009) focused on collective efficacy during an adventure race and reported some evidence about the dynamic structure of this type of efficacy. This study also revealed that successfully progressing teams increased their performance thanks to collective efficacy (Fransen et al., 2014).

The dynamic structure of collective efficacy requires frequent and regular measurement during a particular performance (Myers \& Feltz, 2007). However, administering a survey or a scale during a game is a methodological problem that needs to be solved by researchers due to the rapidly flowing nature of team sports. Therefore, it is necessary to examine the dynamic relationship between collective efficacy and performance by using research designs based on the frequent and regular measurement and to analyze this relationship through multi-level analyses. Developed by Fransen et al. (2014) according to process-based observable behaviors related to collective efficacy, Observational Collective Efficacy Scale for Sports (OCESS) is a suitable alternative scale to solve this methodological problem. The fact that OCESS contains fewer items than its counterparts and these items focus on interpersonal interactions, contributes to ease of administration when there is limited time or in fast-flowing situations where measurement is difficult. Moreover, this scale allows researchers to make observational measurements because it focuses on observable behaviors within a team. At this point, it is thought that the use of continuous observations from the audience (observers) will make the in-game measurement more feasible in a non-invasive manner (e.g. no half-time measurement inside the locker room where athletes could relax and concentrate on their game). What is important here is that it is necessary to train the audience about the concept beforehand and carry out necessary reliability studies (such as interrater reliability; Kimberlin \& Winterstein, 2008). It is believed that this methodological approach, which uses observable behaviors during a performance (however, no such studies have yet been designed to incorporate observational measurement), is more efficient than other measurement tools that have some limitations in measuring possible changes during a performance. In addition, it is more suitable than self-report methods because it is not affected by participants' social desirability bias (Aspland \& Gardner, 2003).

The research has established a link between performance and collective efficacy in dynamic sport situations (Edmonds et al., 2009), thus understanding the dynamic nature of the collective efficacy is a cornerstone in efficacy research in sports. Yet traditional methods for data collection limit the researchers' ability to study the impact of dynamical changes. Faster and more sensitive methods are required for the detection of changes in collective efficacy. The validation of OCESS plays an important role in this effort. Thus, the aim of the current study was to replicate the findings from Fransen et al. (2014) regarding the psychometric qualities of OCESS as a self-reported form in a sample of Turkish athletes.

\section{Methods}

\section{Participants}

The study was conducted with 219 adult athletes residing in Eskişehir and Kastamonu provinces in Turkey, contained 78 females (age $M=21.17, S D=2.74$ years) and 141 males (age $M=21.36, S D=4.29$ years). The participants were selected by using a convenient sampling method. The majority of the participants were professional athletes $(90 \%)$ from team (football, basketball, volleyball, and handball) sports while the rest were recruited from collegiate sports clubs (rugby and swimming). The average years of experience reported by participants in their respective sport was 10.47 
$(S D=4.54)$; and they had an average of 2.87 years of experience in their current team $(S D=2.30)$.

This study was conducted according to the ethical principles of the Declaration of Helsinki and institutional ethical approval was obtained before data collection and analyses. All participants provided informed consent prior to their participation.

\section{Observational Collective Efficacy Scale for Sports}

OCESS is a process-oriented measurement tool intended to capture the dynamic nature of collective efficacy via emphasizing interpersonal interactions. Developed by Fransen et al. (2014) based on observable shared behaviors related to collective efficacy, OCESS is comprised of 5 items each of which is rated on a 7-point scale ranging from 1 (not at all confident) to 7 (extremely confident). The items were preceded by the stem "Rate your confidence, in terms of the upcoming game or competition, that your team has the ability to...". The items from the original version of the OCESS with the means and standard deviations are presented in Table 1. Internal consistency (alpha) coefficient of the original version was .85 , indicating good internal consistency.

\section{Procedure}

Before proceeding to the adaptation of the OCESS, we contacted the first author of the paper by Fransen et al. (2014) to request their approval to adapt and translate the scale. With the permission of the first author, we followed Hambleton and Patsula's (1999) guidelines for instrument adaptation and Brislin's (1986) recommendations for translation in cross-cultural research. The first translation of the OCESS into Turkish was performed independently by three academicians, who are competent in English and the field of the study. The researchers examined the translated versions and sent them to two different academics for back-translation. Later, the appropriacy of the translations was evaluated by comparing the items with English in terms of meaning and grammar, and the Turkish translation of each item was determined. Finally, the adapted scale was finalized after the feedback received from two academicians from the field.

\section{Data collection}

The data for the study were obtained from a descriptive information form and the OCESS. Participation in the study was on a voluntary basis, and the cross-sectional data were collected through a pencil/paper questionnaire either before and or after the training sessions. No time limit was set for the data collection, and participants were instructed to provide feedback for the items to clarify ambiguous wording.

\section{Data analysis}

IBM SPSS and AMOS software (Version 24; IBM, Armonk, NY, USA) were used for data analysis. The following methods were used in the analyses: confirmatory factor analysis, convergent validity, and discriminant validity for construct validation; alpha coefficient, composite reliability, and item-total correlation for reliability. The model-data fit was assessed based on recommended indices: comparative fit index (CFI), Tucker-Lewis Index (TLI), the root mean square error of approximation (RMSEA), the standardized root mean square residual (SRMR), $\chi^{2}, \chi^{2} / S D$. Composite reliability and average variance extracted (AVE) values were calculated to test convergent validity, and maximum shared variance (MSV) and average shared variance (ASV) were calculated to examine discriminant validity. The reliability and discriminant power of the items were examined by calculating item-total correlations and conducting independent samples $t$-test. The intraclass correlation coefficient (ICC, two-way mixed-effects model) was calculated to estimate testretest reliability.

\section{Results}

\section{Confirmatory factor analysis}

Confirmatory factor analysis was performed to confirm the factor structure of the original scale for the sampling of Turkish athletes. In the first analysis, model-data

Table 1

The original items of the Observational Collective Efficacy Scale for Sports with the means and standard deviations

\begin{tabular}{lcc}
\hline Item & Mean & $S D$ \\
\hline React enthusiastically when making a point & 5.56 & 1.56 \\
Have leader figures in the team who believe that we will win this game and express this on the court & 5.98 & 1.45 \\
Have both players in the game and on the bench who cheer enthusiastically & 5.72 & 1.56 \\
Encourage each other during the game & 5.93 & 1.47 \\
Communicate a lot tactically during the game & 5.82 & 1.39 \\
\hline
\end{tabular}


fit was not at a desired level $\left(\chi^{2} / S D=3.24, p=.006\right.$, $\mathrm{CFI}=.97, \mathrm{TLI}=.94, \mathrm{SRMR}=.03, \mathrm{RMSEA}=.10)$. Consequently, we looked at modification indices to determine whether there were any correlated residuals. Considering that $3 \mathrm{rd}$ and 5 th items involved the term "game" and the correlation between these items is thought to be the cause of common method variance because of its power $(r=.50)$, the correlation between error covariances was added to the model as suggested by the software. Fit indices of the model and acceptable values of these indices are displayed in Table 2 . The factor loadings ranged from .38 to .84 as shown in Figure 1. Accordingly, the model-data fit was found to be at a good level.

\section{Convergent and discriminant validity}

In this study, AVE and CR values were calculated as .49 and .82, respectively. As argued by Fornell and Larcker (1981) and Hair, Black, Babin, and Anderson (2010), convergent validity is achieved if AVE is greater than .5 and CR is greater than .6. Although AVE is less than .5, a CR value greater than .6 is sufficient proof for the presence of convergent validity (Fornell \& Larcker, 1981). Hence, it can be concluded that the results provide modest support for the convergent validity of the OCESS.
To provide evidence of discriminant validity for the OCESS, AVE should be greater than MSV and ASV values (Hair et al., 2010). Both MSV and ASV values were calculated as .14, which are less than AVE, suggesting the discriminant validity of the OCESS is assured.

\section{Item analysis}

The analysis showed that corrected item-total correlations of the OCESS ranged between .36 and .72. The independent sample $t$-test for lower 27\% and upper 27\% scores from the items showed a significant relationship $(p<.001)$. Büyüköztürk (2014) states that corrected item-total correlations that are greater than .30 indicate a good discrimination capacity for the items. OCESS items had item-total correlations greater than .50, indicating a good discriminant power. Item analysis results are displayed in Table 3.

\section{Internal consistency and composite reliability}

The reliability of the OCESS was assessed by computing internal consistency (Cronbach's alpha) and CR coefficients. Cronbach's alpha was .80, and the CR was equal to .82 . The $\mathrm{CR}$ value is greater than the rule of thumb threshold of .70 (Hair et al., 2010). The results indicate a good internal consistency for the OCESS.

Table 2

Indices indicate a good model-data fit

\begin{tabular}{lccl}
\hline Indicator & Value & Goodness of fit criteria & Reference \\
\hline$\chi^{2} / S D$ & 2.04 & $<3$ & Kline (2005) \\
Comparative fit index & .98 & $>.90$ & Tabachnick and Fidell (2007) \\
Goodness of fit index & .98 & $>.90$ & Hooper, Coughlan, and Mullen (2008) \\
Tucker-Lewis index & .97 & $>.95$ & Harrington (2009) \\
Standardized root mean square residual & .02 & $<.08$ & Brown (2014) \\
Root mean square error of approximation & .06 & $<.07$ & Steiger (2007) \\
\hline
\end{tabular}

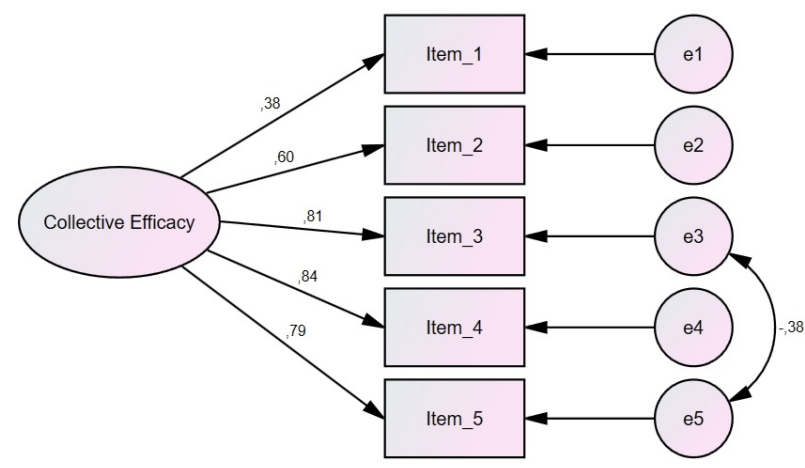

Figure 1. Factor loadings for the Turkish version of the Observational Collective Efficacy Scale for Sports.
Table 3

Item analysis results

\begin{tabular}{lcc}
\hline & $\begin{array}{c}\text { Corrected item } \\
\text { total correlation }\end{array}$ & $\begin{array}{c}t \\
\text { Item no }\end{array}$ \\
\hline 1 & .36 & $9.86^{*}$ \\
2 & .56 & $9.73^{*}$ \\
3 & .65 & $13.80^{*}$ \\
4 & .71 & $11.81^{*}$ \\
5 & .65 & $11.36^{*}$ \\
\hline
\end{tabular}

${ }^{*} p<.001$. 


\section{Test-retest reliability}

We calculated the intraclass correlation coefficient (ICC, two-way mixed-effects model) to assess the testretest reliability of the OCESS. In order to account for the possible changes in collective efficacy, we recruited athletes from collegiate sport clubs with no schedule at least for a week. A total of 33 collegiate athletes filled out the questionnaire with an interval of one week between the test and retest. The ICC for test-retest measurements was .75 . Values of ICC above .75 were considered excellent reliability (Cicchetti, 1994).

\section{Discussion}

This study aimed to carry out an adaptation into Turkish and assess the psychometric properties of the selfreported OCESS, which was developed by Fransen et al. (2014) within the framework of collective efficacy behaviors that is process-oriented.

OCESS is considered to be more functional than the similar scales in the literature as it consists of a few items, focuses on interpersonal interactions, and allows measurement during a performance in a non-invasive manner (observer-report). Moreover, it is an alternative data collection tool to self-report methods since it focuses on observable shared behaviors during a performance (Fransen, Mertens, Feltz, \& Boen, 2017).

The construct validity and reliability analyses of OCESS showed that the scale is a reliable and valid measurement tool for collective efficacy studies to be conducted in Turkish samples. Confirmatory factor analysis supported the unidimensionality of the original version for the sampling consisting of adult athletes from Turkey $\left(\chi^{2} / S D=2.04, \mathrm{CFI}=.98, \mathrm{TLI}=.97\right.$, SRMR $=.02$, RMSEA $=.06$ ). Similarly, Fransen et al. (2016) reported excellent fit indices for the psychometric structure of the OCESS in a Flemish sample with young athletes $\left(\chi^{2} / \mathrm{df}=1.04, \mathrm{CFI}=1.00, \mathrm{TLI}=1.00\right.$, SRMR $=.02, \quad$ RMSEA $=.02)$. According to our results, perfect goodness of fit was obtained after the modification. All the standardized factor loadings were ranged between .60 and .84 with one exception (i.e., .38 for item number 1). Factor loading parameters were weaker for the 1st item but the item was considered necessary to retain because the wording was more explicit and the internal consistency of the scale was acceptable. Also, the present study aims to validate the Turkish version of the OCESS, thus the item in question deemed to be a good indicator of process-oriented collective efficacy in Turkish culture.

Corrected item-total correlations ranged from .36 to .71 . Internal consistency coefficients were .80 , and .82 for alpha and composite reliability, respectively.
In their initial study, Fransen et al. (2014) reported high internal consistency for the scale $($ alpha $=.85)$. Item analysis and two different reliability coefficients showed a satisfactory level of reliability and the ICC for test-retest reliability was found to be excellent (.75).

\section{Conclusion}

In conclusion, the OCESS demonstrates good convergent and discriminant validity, proving that it is a reliable tool for measuring process-oriented collective efficacy in the sample of Turkish athletes. In the present study, the findings provided evidence for the crosscultural applicability of the scale but some limitations should be noted. First, the structure of the scale in this study was tested only with adult athletes. Therefore, it is recommended that the scale should be tested with young athletes, reliability and validity studies should be done accordingly and gender should be considered as a variable regarding measurement invariance. Second, our sample contained athletes from a variety of team sports, however, participants from basketball and swimming were too few in number to make comparisons. Thus we urge researchers to confirm the factorial structure and wording of the items in different sport settings. Third, in this validity and reliability study of the Turkish version of the scale, our approach was to test the OCESS as a self-evaluative questionnaire form as in the original work by Fransen et al. (2014). Future studies, therefore, should be extended to include the observational approach, which was one of the main ideas underlying the development of the OCESS.

\section{Conflict of interest}

There were no conflicts of interest.

\section{References}

Aspland, H., \& Gardner, F. (2003). Observational measures of parent-child interaction: An introductory review. Child and Adolescent Mental Health, 8, 136-143.

Bandura, A. (1997). Self-efficacy: The exercise of control. New York, NY: W. H. Freeman.

Beauchamp, M. R. (2007). Efficacy beliefs within relational and group contexts in sport. In S. Jowett \& D. Lavallee (Eds.), Social psychology in sport (pp. 181-195). Champaign, IL: Human Kinetics.

Brislin, R. W. (1986). The wording and translation of research instruments. In W. J. Lonner \& J. W. Berry (Eds.), Field methods in cross-cultural research (pp. 137-164). Beverly Hills, CA: Sage. 
Brown, T. A. (2014). Confirmatory factor analysis for applied research (2nd ed.). New York, NY: Guilford Publications.

Büyüköztürk, Ş. (2014). Sosyal bilimler için veri analizi el kitabl (19. Bask1) [Data analysis handbook for social sciences (19th ed.)]. Ankara, Turkey: Pegem Akademi.

Chow, G. M., \& Feltz, D. L. (2014). Collective efficacy beliefs and sport. In M. R. Beauchamp \& M. A. Eys (Eds.), Group dynamics in exercise and sport psychology (2nd ed., pp. 298-315). New York, NY: Routledge.

Cicchetti, D. V. (1994). Guidelines, criteria, and rules of thumb for evaluating normed and standardized assessment instruments in psychology. Psychological Assessment, 6, 284-290.

Dithurbide, L., Sullivan, P., \& Chow, G. (2009). Examining the influence of team-referent causal attributions and team performance on collective efficacy: A multilevel analysis. Small Group Research, 40, 491-507.

Edmonds, W. A., Tenenbaum, G., Kamata, A., \& Johnson, M. B. (2009). The role of collective efficacy in adventure racing teams. Small Group Research, 40, 163-180.

Fornell, C., \& Larcker, D. F. (1981). Evaluating structural equation models with unobservable variables and measurement error. Journal of Marketing Research, 18, 39-50.

Fransen, K., Kleinert, J., Dithurbide, L., Vanbeselaere, N., \& Boen, F. (2014). Collective efficacy or team outcome confidence? Development and validation of the Observational Collective Efficacy Scale for Sports (OCESS). International Journal of Sport Psychology, 45, 127-137.

Fransen, K., Mertens, N., Feltz, D., \& Boen, F. (2017). "Yes, we can!" review on team confidence in sports. Current Opinion in Psychology, 16, 98-103.

Fransen, K., Steffens, N. K., Haslam, S. A., Vanbeselaere, N., Vande Broek, G., \& Boen, F. (2016). We will be champions: Leaders' confidence in 'us' inspires team members' team confidence and performance. Scandinavian Journal of Medicine \& Science in Sports, 26, 1455-1469.

Greenlees, I. A., Graydon, J. K., \& Maynard, I. W. (1999). The impact of collective efficacy beliefs on effort and persistence in a group task. Journal of Sports Sciences, 17, 151-158.

Gully, S. M., Incalcaterra, K. A., Joshi, A., \& Beaubien, J. M. (2002). A meta-analysis of team-efficacy, potency, and performance: Interdependence and level of analysis as moderators of observed relationships. Journal of Applied Psychology, 87, 819-832.

Hair, J. F., Black, W. C., Babin, B. J., \& Anderson, R. E. (2010). Multivariate data analysis: A global perspective (7th ed.). Upper Saddle River, NJ: Pearson.

Hambleton, R. K., \& Patsula, L. (1999). Increasing the validity of adapted tests: Myths to be avoided and guidelines for improving test adaptation practices. Journal of Applied Testing Technology, 1, 1-13.

Harrington, D. (2009). Confirmatory factor analysis. Oxford, United Kingdom: Oxford University Press.

Hooper, D., Coughlan, J., \& Mullen, M. R. (2008). Structural equation modelling: Guidelines for determining model fit. Electronic Journal of Business Research Methods, 6, 53-60.

Kimberlin, C. L., \& Winterstein, A. G. (2008). Validity and reliability of measurement instruments used in research. American Journal of Health-System Pharmacy, 65, 2276-2284.

Kline, R. B. (2005). Principles and practice of structural equation modeling (2nd ed.). New York, NY: The Guilford Press.

Myers, N. D., \& Feltz, D. L. (2007). From self-efficacy to collective efficacy in sport: Transitional methodological issues. In G. Tenenbaum \& R. C. Eklund (Eds.), Handbook of sport psychology (3rd ed., pp. 799-819). Hoboken, NJ: Wiley.

Short, S. E., Sullivan, P., \& Feltz, D. (2005). Development and preliminary validation of the collective efficacy questionnaire for sports. Measurement in Physical Education and Exercise Science, 9, 181-202.

Silver, W. S., \& Bufanio, K. M. (1996). The impact of group efficacy and group goals on group task performance. Small Group Research, 27, 347-359.

Stajkovic, A. D., Lee, D. S., \& Nyberg, A. J. (2009). Collective efficacy, group potency, and group performance: Meta-analyses of their relationships, and test of a mediation model. Journal of Applied Psychology, 94, 814-828.

Steiger, J. H. (2007). Understanding the limitations of global fit assessment in structural equation modeling. Personality and Individual Differences, 42, 893-898.

Tabachnick, B. G., \& Fidell, L. S. (2007). Using multivariate statistics (5th ed.). Boston, MA: Pearson Education. 